\title{
Knowledge Sharing Practice and Associated Factors Among Health Care Workers at Public Hospitals in North Shoa, Amhara
}

\author{
Gizew Dessie \\ Department of Human Resource for Health Management, Institute of Public Health, University of Gondar, Gondar, Ethiopia
}

\section{Email address:}

gizew.dessie@gmail.com

To cite this article:

Gizew Dessie. Knowledge Sharing Practice and Associated Factors Among Health Care Workers at Public Hospitals in North Shoa, Amhara. American Journal of Health Research. Vol. 5, No. 5, 2017, pp. 149-153. doi: 10.11648/j.ajhr.20170505.16

Received: August 19, 2017; Accepted: September 4, 2017; Published: October 2, 2017

\begin{abstract}
Knowledge is the most important strategic resource and critical to organizational success. However, practice of knowledge sharing among workers in the health institution is poorly practiced. An institutional based cross- sectional quantitative study supported with qualitative data was conducted from February 30 to March 30/2016 among 291 health care workers for the quantitative data and 10 department heads were interviewed for the qualitative part. Logistic regression was used to assess the presence of association between dependent and independent variables using SPSS at 95\% CI and 5\% margin of error. The study revealed that level of knowledge sharing among health care workers in the selected hospitals was $66.6 \%$. Knowledge sharing opportunity $(\mathrm{AOR}=2.65,95 \% \mathrm{CI}=[1.17-6.01]$, access to technology $(\mathrm{AOR}=2.27,95 \% \mathrm{CI}=[1.17-4.40]$, familiarizing health care workers to technology $(\mathrm{AOR}=3.23,95 \% \mathrm{CI}=[1.28-8.12]$ and trusty relationship $(\mathrm{AOR}=4.78,95 \% \mathrm{CI}=$ [1.73-13.22] were independent predictors for knowledge sharing practice. Even though most of the participants were aware, willing and have an intrinsic motivation to share their knowledge, they practiced it poorly for several reasons. The identified main determinants are access to ICT infrastructure, familiarization to available technologies, trust between staff and knowledge sharing opportunity. Hospitals should enhance trusting relationship among health care workers; create knowledge sharing opportunity; avail technological infrastructure and familiarize health care workers to technology to increase knowledge sharing in the organization.
\end{abstract}

Keywords: Knowledge Sharing Practice, Health Care Workers, Public Hospitals, Ethiopia, North Shoa Zone

\section{Introduction}

Knowledge sharing is defined as a deliberate act that makes knowledge reusable by other people through knowledge exchange [1]. It has been identified as the key component of knowledge management and performance improvement system. Effective knowledge-sharing practices have the potential to give an organization a sustainable competitive advantage [2].

Despite knowledge sharing among different health systems were acknowledged, globally it is poorly practiced [3]. Study conducted in China among referral health care services indicated that $61 \%$ of hospital doctors rated patient-centered $\mathrm{KS}$ as very poor practice [4]. Another study done in Jordan hospitals revealed that knowledge sharing practice among health care workers was $73 \%$ [5].
As indicated by different studies from Ethiopia, knowledge sharing practice of health professionals rages from $(17.7 \%$ at Felege hiwot hospital to $53.95 \%$ in Hawasa selected public hospitals ) due to several factors [6] [7].

Knowledge sharing practice was affected by various factors [8]. Among this top management support, organizational rewards and technological support were strongly associated with knowledge sharing practice as a study done in Taiwan noted [9].

In study conducted in Malaysian public agencies to identify factors that affect knowledge sharing opportunity, awareness of knowledge sharing and trust between staff were significantly correlated with knowledge sharing practice [10].

Studies in Ethiopia have shown that knowledge sharing opportunity, trust between staff, management support, technological support, awareness, motivation to share and 
willingness to share were independent predictors of knowledge sharing among hospital health care workers [11].

The number of healthcare professionals is increasing from time to time in Ethiopia. However there is also high turnover because of different factors. So, to improve and sustain service quality there should be strong knowledge sharing practice among health care workers in public hospitals [12] [13].

The objective of this study was to determine knowledge sharing practice among health workers and to identify determinant factors in hospitals of North Shoa, Amhara. Since there is inadequate evidence on this topic in the study area, findings of this study will serve as important evidence for health administrators, policy makers, health professionals, NGOs and researchers to plan and make interventions to improve knowledge sharing practice in the study area.

\section{Methods}

The study was institutional based cross sectional quantitative study design supported with qualitative data that was conducted from February 30, 20/2016 - March, 30/2016 in North Shoa zone public hospitals, North Shoa, Amhara Regional state.

North Shoa Zone is found in Amhara region and its capital city is Debre Birhan and it is 130 killo metres away from Addis Ababa, capital city of Ethiopia. The catchment population is about 2,093,554 that gets health care service from one referral hospital, three primary hospitals, 86 private health institutions including one hospital, 88 health centres, 389 health posts. The four public hospitals that this study assessed their knowledge sharing practices were Debre birhan referral hospital, Alem ketema Enat primary hospital, Mehal meda primary hospital and Ataye primary hospital which totally consists of 860 workers. Health care workers of the four hospitals actively working during data collection were included in the study population.

The sample size was calculated using both single and double population proportion formula and the single one gave larger sample size with the following assumptions; proportion $49.0 \%$ (which was taken from knowledge sharing practice at Addis Ababa selected public hospitals), 5\% margin of error at $95 \%$ confidence level. The sample size was 291 after adding 10\% for non-respondents. The total sample size was allocated proportionally to all hospitals and to each department within a hospital. The dependent variable was knowledge sharing practice and the independent ones include; organizational factors, individual factors and technological factors.

Knowledge sharing practice was measured using likert scale questionnaires adapted from relevant literatures. Pretest was done on $6 \%$ of the subjects at Deneba Hospital. Data were collected by pre-tested, self-administered questionnaires. The collected data were cleaned, coded and entered to SPSS version 16.0 software. Summary statistics of socio demographic variables were presented using frequency tables. Bi-variate analysis was done and variables with $\mathrm{p}$ - value less than 0.2 were included in the multiple logistic regression analysis. Odds ratio and $95 \%$ confidence intervals were also computed along with the corresponding $\mathrm{p}$-value.

The study was reviewed and approved by Institution Research Review Boards, Institute of Public Health at the University of Gondar. The purpose and the importance of the study were explained and written consent was obtained from each participant. Moreover, confidentiality of the information was assured by coding.

\section{Results}

\subsection{Socio Demographic and Economic Characteristics of Respondents}

A total of two hundred ninety-one questionnaires were distributed to health care workers in the selected hospitals (Alem Ketema Enat, Ataye, Debre Birhan and Mehal Meda) of which 284 were returned valid, giving response rate of $97.6 \%$. Nearly one-third $(31.3 \%)$ of respondents were females. More than three-forth $(76.4 \%)$ respondents were in the age group between 21-30 years. More than half (53.5\%) of respondents were degree holders and about $78.9 \%$ of workers had working experience of within 5 years. A total of 10 key informants were involved in the in depth interview.

Table 1. Socio demographic characteristics of study participants in North Shoa public hospitals, 2016. $(N=284)$.

\begin{tabular}{|c|c|c|c|}
\hline Variable & & Frequency & Percentage \\
\hline \multirow[t]{2}{*}{ Sex } & Female & 89 & 31.34 \\
\hline & Male & 195 & 68.66 \\
\hline \multirow[t]{4}{*}{ Age } & $20-30$ & 217 & 76.4 \\
\hline & $31-40$ & 29 & 10.2 \\
\hline & $41-50$ & 17 & 6.0 \\
\hline & 51 and above & 21 & 7.4 \\
\hline \multirow{2}{*}{$\begin{array}{l}\text { Educational } \\
\text { level }\end{array}$} & Diploma and below & 131 & 46.1 \\
\hline & Degree and above & 153 & 53.9 \\
\hline Profession & Anesthesia & 10 & 3.5 \\
\hline Or & Laboratory & 24 & 8.5 \\
\hline \multirow[t]{7}{*}{ department } & Medical doctor & 27 & 9.5 \\
\hline & Midwifery & 24 & 8.5 \\
\hline & Nurse & 84 & 29.6 \\
\hline & Pharmacy & 24 & 8.5 \\
\hline & x-ray & 11 & 3.9 \\
\hline & Support staff & 76 & 26.8 \\
\hline & Others & 4 & 1.4 \\
\hline \multirow[t]{3}{*}{ Work experience } & 5 years and below & 224 & 78.9 \\
\hline & $6-10$ years & 8 & 2.8 \\
\hline & Greater than 10 years & 52 & 18.3 \\
\hline Monthly & Below 1000 & 31 & 10.9 \\
\hline \multirow[t]{2}{*}{ Salary } & $1000-3000$ & 149 & 52.5 \\
\hline & Greater than 3000 & 104 & 36.6 \\
\hline Marital & Married & 76 & 26.76 \\
\hline \multirow[t]{2}{*}{ Status } & Unmarried & 186 & 65.49 \\
\hline & Divorced & 22 & 7.75 \\
\hline
\end{tabular}

\subsection{Organizational Characteristics}

Only $34(12 \%)$ of respondents have agreed that there is resource for knowledge sharing activity and openness to share knowledge with in the study hospitals was found to be 
$75.3 \%$.

In this study $65.5 \%$ of respondents have agreed that there is supportive leadership in the study hospitals.

Table 2. Organizational factors for knowledge sharing practice at public hospitals in North Shoa, 2016. (N=284).

\begin{tabular}{llll}
\hline Variable & Response & Frequency & Percent \\
\hline Resource availability & No & 250 & 88.0 \\
& Yes & 34 & 12.0 \\
Supportive leadership & No & 98 & 34.5 \\
& Yes & 186 & 65.5 \\
Openness to share & No & 67 & 23.6 \\
& Yes & 217 & 76.4 \\
Opportunity to share & No & 101 & 35.5 \\
& Yes & 183 & 64.5 \\
\hline
\end{tabular}

\subsection{Technological Characteristics}

Half $(50.3 \%)$ of participants have agreed that there is ICT access for knowledge sharing and $20.1 \%$ of respondents have agreed that they were familiar with the available technology for knowledge sharing.

Table 3. Technological factors for knowledge sharing practice at public hospitals in North Shoa, 2016. (N=284).

\begin{tabular}{llll}
\hline Variable & Response & Frequency & Percent \\
\hline ICT Availability & No & 141 & 49.7 \\
& Yes & 143 & 50.3 \\
IT familiarization & No & 227 & 79.9 \\
& Yes & 57 & 20.1 \\
\hline
\end{tabular}

\subsection{Individual characteristics}

This study revealed that $72.2 \%$ of the respondents had trust on others' knowledge. A 39 years old matron said, "There are individuals who share their knowhow and ready to accept and apply the knowledge they get from others. On the other hand there are individuals who are reluctant to accept or to share knowledge with colleagues".
Table 4. Individual factors for knowledge sharing practice at public hospitals in North Shoa, 2016. (N=284).

\begin{tabular}{llll}
\hline Variable & Response & $\begin{array}{l}\text { Frequenc } \\
\mathbf{y}\end{array}$ & Percent \\
\hline Intrinsic motivation & No & 28 & 9.90 \\
& Yes & 256 & 90.10 \\
Extrinsic motivation & No & 203 & 71.50 \\
& Yes & 81 & 28.50 \\
Trust & No & 79 & 27.80 \\
& Yes & 205 & 72.20 \\
Awareness & No & 19 & 6.70 \\
\multirow{2}{*}{ Willingness to share } & Yes & 265 & 93.30 \\
& No & 36 & 12.68 \\
Fear of losing competitiveness & Yes & 248 & 87.32 \\
\multirow{3}{*}{ Job satisfaction } & No & 211 & 79.6 \\
& Yes & 73 & 20.4 \\
& No & 74 & 26.06 \\
\hline
\end{tabular}

\subsection{Knowledge Sharing Practice}

In this study level of knowledge sharing practice among health care workers in the selected hospitals was found to be $66.6 \%$.

Almost all key informants said, "There is knowledge sharing practice in the hospital but not as active as it should be".

\subsection{Factors Associated with Knowledge Sharing Practice}

The result of bi-variable analysis revealed that sex, educational level, work experience, job satisfaction, intrinsic motivation, trust on others' knowledge, access to technology, health care workers familiarity to technology and knowledge sharing opportunity were found to be associated factors for knowledge sharing practice.

But the results of multi-variate analysis noted that only knowledge sharing opportunity $(\mathrm{AOR}=2.65,95 \% \mathrm{CI}$ $=[1.17-6.01]$, access to technology $(\mathrm{AOR}=2.27,95 \% \mathrm{CI}=$ [1.17-4.40], familiarizing health care workers to technology $(\mathrm{AOR}=3.23,95 \% \mathrm{CI}=[1.28-8.12]$ and trust between staff $(\mathrm{AOR}=4.78,95 \% \mathrm{CI}=[1.73-13.22]$ were found to be independent predictors for knowledge sharing practice.

Table 5. Bivariate and multi-variate analysis on Knowledge sharing practice at public hospitals in North Shoa, 2016(N=284).

\begin{tabular}{|c|c|c|c|c|c|}
\hline \multirow[t]{2}{*}{ Variable } & & \multicolumn{4}{|c|}{ Knowledge sharing practice } \\
\hline & & Yes & No & $\operatorname{COR}(95 \% \mathrm{CI})$ & AOR(95\% CI) \\
\hline \multirow{3}{*}{ Educational level } & Diploma and below & 71 & 62 & $3.267(1.951,5.473)$ & $1.63(0.58,4.58)$ \\
\hline & Degree and above & 118 & 33 & 1 & 1 \\
\hline & Not motivated & 131 & 72 & 1 & \\
\hline \multirow[t]{2}{*}{ Intrinsic motivation } & Motivated & 163 & 93 & $7.42(1.72,31.96)$ & $3.26(0.56,19.10)$ \\
\hline & Not motivated & 26 & 2 & 1 & 1 \\
\hline \multirow[t]{2}{*}{ Trust between staff } & Yes & 116 & 89 & $7.74(3.39,17.63)$ & $4.78(1.73-13.22)^{*}$ \\
\hline & No & 73 & 6 & 1 & 1 \\
\hline \multirow[t]{2}{*}{ ICTs access } & Yes & 81 & 62 & $2.51(1.50,4.18)$ & $2.27(1.17-4.40)^{*}$ \\
\hline & No & 108 & 33 & 1 & 1 \\
\hline \multirow[t]{2}{*}{ Familiarization to IT } & Yes & 27 & 30 & $2.77(1.53,5.02)$ & $3.23(1.28-8.12)^{*}$ \\
\hline & No & 162 & 65 & 1 & \\
\hline \multirow[t]{2}{*}{ Knowledge Sharing Opportunity } & Yes & 108 & 75 & $2.812(1.589,4.979)$ & $2.65(1.17-6.01)^{*}$ \\
\hline & No & 81 & 20 & 1 & 1 \\
\hline
\end{tabular}

$*=\mathrm{P}<0.05$ 


\section{Discussion}

The main purpose of this study was to investigate knowledge sharing practice among health care workers and to identify the main factors that affect knowledge sharing practice among health care workers at public hospitals in North Shoa Zone.

In this study knowledge sharing practice among health care workers was found to be $66.6 \%$. Findings of this study is higher than similar studies conducted in Addis Ababa health bureau at selected public hospitals (49.0\%) [14], Mekele at selected public hospitals (49.18\%) [13], Hawasa at selected public hospitals (53.95) [7] and in Bahir Dar at Felege hiwot referral hospital $(17.7 \%)$ [6]. But it is lower than a study done in Jordanian Hospitals (73\%) [5]. The most possible reasons for the difference might be the difference in infrastructure, staff awareness, management support, resource allocation, and geographical location.

Of the variables, trust on others' knowledge had positive significant association with knowledge sharing practice. This finding is consistent with studies done in Taiwan and Malaysia from outside [2] [15] and selected public hospitals in Addis Ababa, Mekele, Hawasa and Bahir Dar within Ethiopia [6] [7] [13] [14].

The other predictor variable that has positive significant association with knowledge sharing is opportunity to share knowledge. This study showed that the higher knowledge sharing opportunity in the hospital, the more likely health care workers to practice knowledge sharing. This finding is consistent with studies done in Mekele, Bahir Dar and Hawasa [6] [7] [13].

Technological infrastructure availability and familiarity to the available technology had positive significant association with knowledge sharing practice in this study. This finding is supported by a study done in China[8] and Ethiopia [11] [14]. But a similar study done in Mekele showed that technological factors have no significant association with knowledge sharing practice[13]. This variation can be due to organizational system and study time differences.

\section{Limitations of the Study}

The finding of the research would be more representative if it were conducted widely by including other different health organizations in different region of Ethiopia. But due to time, labor and money constraints, the study is limited to public hospitals in North Shoa under the Amhara National Regional Health Bureau.

\section{Conclusion}

The following recommendations are given based on the study of knowledge sharing practice with a view to further enhancing knowledge sharing practice in North Shoa Hospitals, in particular and in health sector, in general.

Even though most of the participants were aware, willing and have an intrinsic motivation to share their knowledge, they practiced knowledge sharing poorly for several reasons. The identified main determinants are access to ICT infrastructure, familiarization to available technologies, trust on others' knowledge and knowledge sharing opportunity.

\section{Recommendations}

Most of health care workers are having work overload that creates time shortage to participate in the knowledge sharing activity of the hospital. The hospital should better use web technology so that staffs can easily create, organize, search and access new knowledge at any time. To realize this there should be a concerted effort to familiarize all health care workers to the available technologies.

The hospital should arrange a formal knowledge sharing opportunity like regular meeting, seminar, and work shop where staff can share knowledge by assigning appropriate resources (time, budget and infrastructure like meeting place, communication tools, especially modern IT infrastructures).

The hospital should create a condition where the socialization of staff increases by preparing different ceremonies. These are a good way of developing trust among them and increase the chance of informal opportunity to knowledge transfer.

Conducting further Study at national level giving all public hospitals equal opportunity is very important to generalize knowledge sharing practice of health care workers in Ethiopia.

Future research may take other organizational variables such as, organizational size and type of environment (rural and urban) into account, including quality of knowledge sharing.

\section{Acknowledgements}

Heartfelt gratitude goes to my dedicated advisors Dr. Gashaw Andargie and Mr. Melaku Kindie, especially Mr. Melaku Kindie for his concern, devotion and empathy in helping me while I was in a difficult situation that was really far more than what was expected from an adviser.

My second gratitude points to Measho Gebreslassie for his invaluable support, advice, empathy and friendly approach from its start to completion which was impossible without him. I want also to acknowledge my families and friends who were in my side during the study.

\section{Conflict of Interest Statement}

The author declares that he has no competing interests.

\section{References}

[1] Kim S, Lee. H, editors. Employee knowledge sharing capabilities in public and private organizations: Does organizational context mat2.Liao S-h, Chang J-c, Cheng S-c, Kuo C-m. Employee relationship and knowledge sharing. Knowledge Management Research \& Practice. 2004; 2(24-34). 
[2] WHO. WHO. Knowledge Management Strategy. 2004.

[3] J Z, Q L, Y Y, Z L, P F. Investigation of information interaction between urban hospital and community health service centre based on communication in medical staff. http://dx.doi.org/10.3969/j.issn.1003 0743.2011.07.026. Chinese Health Economics 2011;30:81-3.

[4] T Z, Alhalhouli, Hj ZB, Hassan, M A, Abualkishik. An Updated Model to Enhance Knowledge Sharing among Stakeholders in Jordanian Hospitals Using Social Networks. Middle-East Journal of Scientific Research. 2013;18(8):108998 .

[5] A. A. knowledge sharing among health professionals the case of Felegehiwot referral hospital Bahirdar. 2010.

[6] GEBREHIWOT AA. ASSESSMENT OF KNOWLEDGE SHARING PRACTICES AND CONTINUOUS LEARNING COMMITMENT OF HEALTH CARE PROFESSIONALS IN HOSPITALS IN HAWASSA. 2014.

[7] Zhou L, Nunes MB. Barriers to knowledge sharing in Chinese healthcare referral services: an emergent theoretical model. 2016.

[8] Lin H-F. Effects of extrinsic and intrinsic motivation on employee knowledge sharing intentions. Journal of Information Science. 2007;33(135).
[9] B M, M Z. The Impact of Individual Factors on Knowledge Sharing Quality. Journal of Organizational Knowledge Management 2010.

[10] Yalow T. Assessment of Knowledge Sharing Practices Among Healthcare Professionals. 2011.

[11] Asemahagn MA. Knowledge and experience sharing practices among health professionals in hospitals under the Addis Ababa health bureau, Ethiopia avilable at http://www.biomedcentral.com/1472-6963/14/431. BMC Health Services Research2014(14):431.

[12] Gebretsadik T, Mirutse G, Tadesse K, Terefe W. Knowledge Sharing Practice and its Associated Factors of Healthcare Professionals of Public Hospitals, Mekelle, Northern Ethiopia. American Journal of Health Research. 2014;2(5):241-6.

[13] Asemahagn MA. Knowledge and experience sharing practices among health professionals in hospitals under the Addis Ababa health bureau, Ethiopia. BMC Health Services Research. 2014;14:431.

[14] M Z, B M. Is there a Relationship between Knowledge Sharing Practice and the Quality of Service Delivery? A Case Study in Three Government Agencies in Malaysia. Journal of Knowledge Management Practice 2009;10(1). 